\title{
CUIDAR E EDUCAR NA CRECHE: O PLANEJAMENTO PEDAGÓGICO E A ATUAÇÃO DAS AUXILIARES DE CLASSE
}

\author{
CARING AND EDUCATING AT THE NURSERY: PEDAGOGICAL PLANNING AND \\ THE PERFORMANCE OF CLASS AID
}

\section{CUIDAR Y EDUCAR EN LA GUARDERÍA: LA PLANIFICACIÓN PEDAGÓGICA Y LA ACTUACIÓN DE LAS AUXILIARES DE CLASE}

\author{
Livia Karen Figueredo de Jesus \\ Universidade Federal da Bahia - Brasil
}

Karina de Oliveira Santos Cordeiro

Universidade Federal do Recôncavo da Bahia - Brasil

\begin{abstract}
Resumo: O presente artigo tem como objetivo apresentar os resultados de uma pesquisa acadêmica sobre as relações entre professoras e auxiliares de classe da Educação Infantil durante o planejamento pedagógico. O objetivo geral do estudo foi compreender como as auxiliares se veem profissionalmente e que lugar elas ocupam no Centro de Educação Infantil. Para a escrita desse artigo, traremos as discussões de uma das categorias que emergiu no percurso da pesquisa, qual seja: "As auxiliares de classe e o planejamento pedagógico". O lócus da pesquisa foi um Centro de Educação Infantil público do município de Amargosa - Bahia. Trata-se de uma pesquisa qualitativa, utilizamos como instrumentos metodológicos a entrevista semiestruturada e a observação. Nesse sentido, realizamos o debate acerca da integração do cuidar e do educar, tendo em vista as relações que se estabelecem entre professoras e auxiliares de classe na elaboração do planejamento pedagógico. Identificamos que, em algumas situações durante as entrevistas, as trabalhadoras apontaram a importância da integração, e até conseguiram indicar as possibilidades de ações para a efetivação da indissociabilidade do cuidar e do educar, contudo, em outros momentos da observação, foi possível identificar que de fato havia uma separação. É preciso dizer que a superação não se configura como algo fácil. Mas ela é possível, por meio da reestruturação no que diz respeito à divisão entre as trabalhadoras, reconhecendo que cuidar e educar são atribuições docentes.
\end{abstract}

Palavras chave: Cuidar e educar; Planejamento; Auxiliares de classe.

\begin{abstract}
This article aims to present the results of academic research on the relationship between teachers and class assistants in Early Childhood Education during pedagogical planning. The general objective of the study was to understand how the assistants see themselves professionally and what place they occupy in the Child Education Center. For the writing of this article, we will bring the discussions of one of the categories that emerged in the course of the research, namely: "Class auxiliaries and pedagogical planning". The locus of the research was a public Child Education Center in Amargosa Bahia. This is qualitative research, using semi-structured interviews and observation as methodological tools. In this sense, we held the debate on the integration of care and education, because of the relationships that are established between teachers and class assistants in the preparation of pedagogical
\end{abstract}


planning. We identified that in some situations during the interviews, the workers pointed out the importance of integration, and even managed to indicate the possibilities of actions for the effectiveness of the inseparability of care and education, however, in other moments of observation, it was possible to identify that fact there was a separation. It must be said that overcoming is not an easy task. But it is possible, through restructuring concerning the division between workers, recognizing that caring and educating are teaching duties.

Keywords: Care and education; Planning; Class assistants.

Resumen: El presente artículo tiene como objetivo presentar los resultados de una investigación académica acerca de las relaciones entre maestras y auxiliares de clase de la educación infantil durante la planificación pedagógica. El objetivo general del estudio fui comprender como las auxiliares se miran profesionalmente y que sitio ellas ocupan en el Centro de Educación Infantil. Para la escrita de ese artículo, traeremos las discusiones de una de las categorías que emergió en la ruta de la investigación, cual sea: "las auxiliares de clase y la planificación pedagógica". El locus de la investigación fui un Centro de Educación Infantil público del condado de Amargosa - Bahia. Se trata de una investigación cualitativa, utilizamos como metodológicos la entrevista medio estructurada y la observación. En ese sentido, realizamos el debate sobre la integración del cuidar y del educar, teniendo en cuenta las relaciones que se establecen entre maestras y auxiliares de clase en la elaboración de la planificación pedagógica. Hemos identificado que, en algunas situaciones durante las entrevistas, las trabajadoras apuntaran la importancia de la integración, y hacia lograron éxito en indicar las posibilidades de acciones para la efectuación de la inseparabilidad del cuidar y del educar, todavía, en otros momentos de la observación, fue posible identificar que de facto había una separación. É necesario decir que la superación no se configura como algo fácil. Sino ella es posible, por medio de la reestructuración en lo que se refiere a la división entre las trabajadoras, reconociendo que cuidar y educar son asignaciones docentes.

Palabras-clave: Cuidar y educar; Planificación; Auxiliares de clase.

\section{Introdução}

As instituições de Educação Infantil, mais especificamente a creche, apresentam características diferenciadas de outras instituições educativas. A creche, por realizar um atendimento em período integral, em sua maioria, para crianças de 0 a 3 anos, necessita de um trabalho diferenciado por parte das profissionais. Nessas instituições, além do trabalho educativo, o vínculo com as ações do cuidado é ainda maior. É preciso dizer que usaremos em todo o texto a designação da professora e das auxiliares de classe no feminino, uma vez que todos os sujeitos de nossa pesquisa foram mulheres. Desse modo, demarcamos desde o início do nosso trabalho que o cuidar e o educar são indissociáveis e necessários no fazer cotidiano das creches.

Tendo em vista a importância de pensar as relações entre as mulheres que atuam na Educação Infantil, especificamente na creche, realizamos um estudo tendo como questão norteadora compreender quem são as auxiliares de classe e que lugar profissional elas ocupam no Centro de Educação Infantil da rede municipal de Amargosa - Bahia. O objetivo geral do estudo foi compreender como as auxiliares se veem profissionalmente e que lugar elas ocupam no Centro de Educação Infantil. Os resultados da pesquisa apontaram para oito categorias, a 
saber: O processo de observação da prática; Aspectos pessoais; Condições de trabalho; Aspectos formativos; As auxiliares de classe e o planejamento pedagógico; Saberes mobilizados na prática; Cuidar e educar em uma instituição de Educação Infantil e Quem são, e que lugar ocupam as auxiliares. Para a escrita desse artigo, optamos pelos dados da seguinte categoria "As auxiliares de classe e o planejamento pedagógico", ao tempo em que realizamos o debate acerca da integração do cuidar e do educar, tendo em vista as relações que se estabelecem entre professoras e auxiliares na elaboração do planejamento pedagógico.

Ao longo do estudo consideramos a integração do cuidar e do educar entendo-os como indissociáveis e parte essencial do desenvolvimento do trabalho no âmbito da creche. Além disso, refletimos sobre a divisão e hierarquização do trabalho entre as professoras e as auxiliares de classe que exercem sua atividade no espaço da sala de aula, não são reconhecidas como professoras e vivenciam condições de trabalho diferenciadas, fato esse que, por vezes, provoca uma separação entre as ações de cuidado e de educação.

As reflexões sobre como o binômio cuidar e educar tem se dado no âmbito da creche são importantes para a área educacional, bem como para as proposições de política públicas que assegurem a indissociabilidade do cuidar e do educar. Desse modo, é necessário propor as discussões sobre a separação laboral entre as pessoas que realizam as ações de cuidar / educar, pois, tais questões podem afetar a construção de uma Educação Infantil de qualidade em que a criança tenha seu direito garantido de forma efetiva. Assim, esse artigo tem o objetivo de colaborar com o debate acerca do binômio cuidar e educar na creche e das relações laborais que se estabelecem nesses espaços, mas especificamente as ações de planejamento pedagógico das atividades.

Este texto está organizado em quatro partes, sendo que na primeira tem-se uma base teórica que auxiliará na compreensão sobre o binômio cuidar e educar. Já no segundo momento discutimos os aspectos metodológicos utilizados durante a pesquisa. $\mathrm{Na}$ terceira parte apresentamos e analisamos os dados pela pesquisa mantendo um diálogo com referenciais teóricos e por último têm-se as palavras finais.

\section{Cuidar e educar: um binômio indissociável?}

O binômio cuidar e educar está presente nas instituições de Educação Infantil, principalmente na creche, desde a sua origem, entretanto, as práticas ocorriam a partir de concepções que se diferem das que se realizam atualmente. Isso porque essas instituições tiveram em sua origem, aqui no Brasil, as ações marcadas por um caráter assistencialista, e sua criação foi pautada pela necessidade do cuidado com as crianças na ausência do cuidado 
familiar, uma vez que as mães precisavam sair do contexto doméstico para trabalhar em outros espaços (SOUZA, RIOS e OLIVEIRA, 2020). Desse modo, a creche, no Brasil, surge para atender uma necessidade das mães trabalhadoras e não das crianças, como podemos confirmar na afirmação de Kuhlmann Jr. "A creche, para bebês, cumpriria uma função de apoio à família e seria exclusivamente para quando as mães necessitassem trabalhar." (KUHLMANN JR. 2000, p. 472). Assim, essa instituição tinha a função e o objetivo de cuidar, no sentido de proteger, pois se tratava, naquela época, de uma compreensão de que as crianças eram seres indefesos, que ficariam expostas aos perigos da vida.

Aliada à necessidade da mãe, estava ligada uma questão de classe social, uma vez que, geralmente, as crianças que precisavam ir para essas instituições eram aquelas que não tinham quem as cuidassem $\mathrm{e}$ as protegessem enquanto as mães trabalhavam (SILVA, FRANCISCHINI, 2012). O caráter assistencial do cuidar no surgimento da creche, no sentido de abrigar essas crianças e essa infância, reforçava a ideia do cuidar como algo fraterno e maternal, e que essa instituição servia apenas para isso. Nesse sentido, a creche vai servir no Brasil, em um primeiro momento, como um espaço para resguardar a infância pobre desse país, nesta perspectiva, Abramowicz afirma que (2003, p. 14) "as creches são os equipamentos destinados às crianças pobres e às classes populares".

Deve-se considerar que a educação, que se refere aos ensinamentos do modo de viver em sociedade, está presente em todos os nossos atos, aprendemos na vivência com o outro e nas relações que estabelecemos. Desse modo, podemos acreditar que ocorriam atos educativos nesses estabelecimentos, mesmo que eles não acontecessem de maneira intencional. Nesse sentido, Azevedo (2013, p. 96) afirma que:

[...] de acordo com os dados históricos, mesmo aquelas instituições que acolhiam crianças pobres, com a função social de filantropia, ofereciam algum tipo de educação, embora não houvesse intenção declarada de fazê-lo. Isso mostra que os adultos que lidavam com elas ao mesmo tempo que pensavam que apenas delas cuidavam, também estavam transmitindo a elas valores crenças, modos culturais de convivência, ou seja, estavam educando-as. (AZEVEDO, 2013, p. 96).

Assim, mesmo que sem a intenção, se educava as crianças que frequentavam esses estabelecimentos, ainda que em algumas situações não se levassem em conta os aspectos no que tange o desenvolvimento cognitivo, motor e psicossocial na realização das atividades. $\mathrm{O}$ que as crianças aprendiam estava mais ligado à vivência em sociedade, como aponta a autora supracitada. E é possível perceber como o processo educativo pode estar presente em atividades relacionadas ao cuidado, seja na alimentação ou nos momentos de higiene, por exemplo. 
Desse modo, fica claro que mesmo nos momentos em que se pensava que só estava presente o cuidado com o corpo, estava ocorrendo um processo educativo, não nos moldes que esperamos hoje, mas se ensinavam as crianças a vivência em sociedade, aspectos morais, etc. Elas aprendiam aspectos da cultura humana.

Então, se durante processos de cuidado diário as crianças também são educadas, podemos observar que não há uma separação entre os atos de cuidar e de educar, no desenvolvimento do trabalho com crianças, principalmente no âmbito da creche. Assim, o profissional que cuida também educa e o que educa também deve cuidar. Mas não é isso que observamos nas instituições de Educação Infantil, pois há uma divisão nítida entre as trabalhadoras que cuidam e das que educam.

No que diz respeito aos aspectos formativos, não há legislação a nível nacional que regulamente a função de auxiliar de classe, como não há registro da função na listagem das ocupações do Cadastro Brasileiro de Ocupações (CBO), o que indica que não há também uma formação específica. Como não há essa regulamentação acerca da formação, a escolha de tal requisito para a realização da função tem ficado a cargo dos gestores municipais, fato que ocasiona uma disparidade, pois em algumas cidades é solicitado o diploma de magistério e em outras o do Ensino Médio completo. Na primeira situação temos a utilização de um perfil profissional do professor, no entanto, não é essa a função ocupada. Já com a exigência do Ensino Médio, temos a atuação de um indivíduo no âmbito da sala de aula, que não dispõe de conhecimentos específicos que são necessários para o desenvolvimento do trabalho docente na creche (FREIRE e FERREIRA, 2020).

Nesse sentido, a falta de formação, por vezes, as impossibilita de traçarem objetivos e ações que proporcionem o desenvolvimento integral das crianças, pois há a ausência de conhecimentos específicos acerca das teorias da educação. Assim, concordamos com Campos (1994, p. 33) ao afirmar que "No que se refere aos aspectos ligados ao desenvolvimento cognitivo, é razoável supor que, na maioria dos casos, o contato com o adulto mais instruído resultará em experiências menos limitadas para a criança”. Não só mais instruído, mas com clareza de como deve ser realizado o trabalho com crianças e mais especificamente de 0 a 3 anos, ou seja, com formação e conhecimentos específicos.

Se tratando do binômio cuidar e educar e da diferenciação das profissionais, Tiriba (2005, p. 66) afirma que:

O binômio cuidar e educar é geralmente, compreendido como um processo único, em que as duas ações estão profundamente imbricadas. Mas, muitas vezes, a conjunção sugere a idéia de duas dimensões independentes: uma que se refere ao corpo e outra aos processos cognitivos. Nos textos acadêmicos, nas propostas pedagógicas, nas práticas, assim como nas falas de profissionais 
de creches, muitas vezes, mais que integração, o binômio expressa dicotomia. Em razão de fatores socioculturais específicos de nossa sociedade, essa dicotomia alimenta práticas distintas entre profissionais que atuam lado a lado nas escolas de educação infantil, especialmente nas creches: as auxiliares cuidam, e as professoras realizam atividades pedagógicas. (TIRIBA, 2005, p. 66 , grifos da autora).

Desse modo, para desenvolver o cuidado com o corpo temos as auxiliares de classe que têm condições de trabalho diferente das professoras. O trabalho desenvolvido pelas auxiliares refere-se ao cuidado, como apontado pela autora supracitada, enquanto o trabalho realizado para as atividades "educativas" é feito pelas professoras. Marcando, assim, nas práticas diárias a separação entre cuidado e educação. Nesse sentido, temos uma divisão social do trabalho e efetivamente a separação dos atos educativos e de cuidado. O que vai contra a tendência que vem sendo discutida e indicada pelos estudiosos e pesquisadores da área, que é a integração do educar e do cuidar. Além disso, descumpre o garantido em documentos legais, tal como as Diretrizes Curriculares Nacionais para a Educação Infantil (BRASIL, 2010).

Sobre a integração do cuidar e do educar, Azevedo (2013, p. 100) garante que:

Integrar cuidado e educação se tornou um slogan da Educação Infantil e teve alcance significativo na área, inclusive nos espaços de atendimento à criança de até 6 anos, mas, infelizmente, apenas enquanto discurso. Foi muito discutido e muito divulgado, mas parece não ter alcançado o devido entendimento por parte dos professores que atuam com as crianças. (AZEVEDO, 2013, p. 100).

Considerando a afirmação de Azevedo (2013), a perspectiva abordada por estudiosos não é totalmente negada nas instituições de Educação Infantil, pois, no discurso, há um movimento para a integração do cuidar e do educar. Porém, o que é mais significativo para a mudança de concepção é o real entendimento do que significa a palavra integração nesse contexto. E como consequência desse entendimento temos a mudança de atitude.

É preciso que as profissionais que atuam na Educação Infantil tenham clareza quanto suas responsabilidades enquanto educadoras de crianças. E que ao realizarem as atividades tenham atitudes e ações que priorizem e efetivem a integração do cuidar e do educar na prática. É necessário que ao realizar atividades do cuidar se tenha a intenção de promover uma ação educativa, como, por exemplo, o banho pode se tornar um excelente momento para a aprendizagem, sendo assim, um ato pedagógico.

Todavia, para que a integração entre o cuidar e o educar saia do discurso e se efetive na prática, é necessária a compreensão por parte de toda a equipe de funcionários das instituições de Educação infantil, principalmente das professoras, pois são elas que realizam o trabalho 
diário com as crianças, que o cuidado e educar devem ser ações integradas, uma vez que só a compreensão efetiva dessa integração poderá propor mudança de atitude.

Compreender o papel educativo das atividades de cuidado também é indispensável para pensar a construção da identidade profissional das mulheres que trabalham nas instituições de Educação Infantil, independente das possíveis divisões laborais. Pois, como há a separação das pessoas que atuam, é como se nas atividades não houvesse a integração entre cuidado e educação, pois uma cuida e a outra educa.

Entendemos que muitos são os fatores que influenciam para a não integração do cuidar e do educar. E um deles é a identidade, entendida como a percepção que o sujeito tem de si e como o outro o compreende, ou a ausência de ambas, que influencia e muito no desempenho e na realização do trabalho dos indivíduos, sendo que, ao mesmo tempo a realização do trabalho influencia na construção da compreensão de si, ou seja, da identidade (DUBAR, 2005). Deste modo, corroboramos com Azevedo (2013) quando aponta que um dos fatores para a manutenção dessa dicotomia entre o cuidar e o educar é a falta de identidade das profissionais que atuam nas instituições de Educação Infantil. Acerca disso ela afirma que:

Fato que contribui para a existência desse dilema é que os adultos que lidam com as crianças na instituição de atendimento infantil continuam sem identidade. Eles não têm clareza da importância do seu papel na instituição. Alguns, por terem formação profissional e pela própria função que desempenham na instituição - professor -, se negam a trocar uma fralda, pois consideram que não se formaram para serem 'babás'. Outros, por não terem a formação profissional e desempenham funções secundárias - auxiliares -, limitam-se aos cuidados de higiene e alimentação e quando, solicitados a participar de uma atividade que seja tarefa do 'professor' negam-se igualmente, alegando que não ganham salário suficiente para isso. (AZEVEDO, 2013, p. 100).

Assim, a falta de identidade apontada pela autora, por parte das educadoras da Educação Infantil, contribui para a manutenção da dicotomia cuidar/educar. E junto com a dicotomia podemos encontrar a distinção entre os dois indivíduos, o que cuida e o que educa. Existe a auxiliar de classe que é quem cuida, troca fralda, dá banho e auxilia na alimentação. E tem-se a professora que é responsável por planejar e desenvolver atividades que proporcionam e potencializam o desenvolvimento cognitivo e motor das crianças, como preconizado na Lei de Diretrizes e Bases da Educação Nacional (LDB) (BRASIL, 1996).

Marcados por uma relação cíclica em que a identidade influencia na realização do trabalho e a realização do trabalho influencia na identidade, podemos notar que o modo como as mulheres desempenham a sua função é influenciado pela sua identidade (DUBAR, 2005). Do mesmo modo, o processo desenvolvido durante o desempenho do seu trabalho é parte 
fundamental para o processo de formação identitária. Como garante Dubar (2005, p. 257) ao afirmar que:

É porque sua identidade de trabalhador ou trabalhadora, a identidade para si, se forjou na aprendizagem in loco, na aprendizagem direta do trabalho ("aprende-se olhando e tocando") na aquisição de saberes práticos na experiência direta das tarefas a realizar. (DUBAR, 2005, p. 257, grifos e marcações do original).

Porém, se a prática desenvolvida pela auxiliar não é considerada pedagógica e se ela não pode se reconhecer como professora, visto que não é esse o lugar profissional ocupado, a sua identidade também não será de educadora e, consequentemente, o seu trabalho não será desenvolvido considerando os aspectos educacionais. E essa falta de identidade de educadora, de professora, pode reforçar a ideia de cuidar e educar de forma dissociada.

Dessa forma, se faz necessário uma mudança na forma que tem se compreendido e vivenciado a Educação Infantil no âmbito da creche, no que diz respeito à divisão das atividades entre o cuidar e o educar (CORDEIRO, SODRÉ, 2008). É necessário romper com essa divisão, uma vez que as ações desenvolvidas na sala de aula são responsabilidade docente, pois é ele o profissional habilitado, como assegura o artigo 61 da LDB (BRASIL, 1996).

\section{Percurso trilhado}

Por tratar-se de uma pesquisa no campo educacional, optamos pela abordagem qualitativa, pois entendemos que ela seria o melhor caminho para o desenvolvimento do estudo. Ao tratarmos de pesquisa qualitativa a compreendemos, a partir de Sandín Esteban (2010, p. 127), como:

[...] uma atividade sistemática orientada à compreensão em profundidade de fenômenos educativos e sociais, a transformação de práticas e cenários socioeducativos, à tomada de decisões e também ao descobrimento e desenvolvimento de um corpo organizado de conhecimentos. (SANDÍN ESTEBAN, 2010, p. 127).

Quanto a identificação do lócus, o estudo foi realizado em um Centro de Educação Infantil que é mantido pela Prefeitura Municipal de Amargosa - Bahia através da Secretaria Municipal de Educação. A referida instituição fica localizada em um Bairro periférico da cidade, e atende um público diverso, mas que, em sua maioria é da classe popular.

O primeiro passo da pesquisa foi a ida ao Centro de Educação Infantil, a fim de estabelecer um primeiro contato com o lócus e com os colaboradores. Nesse primeiro contato falamos com a gestora e explicamos como ocorreria o estudo, o nosso objetivo, bem como apresentamos as etapas da pesquisa. Ao final dessa conversa inicial, tivemos a liberação para 
realizar a investigação científica na instituição. Após o contato com a direção, fomos falar com as auxiliares de classe e as professoras que possuíam certa estabilidade através de processo seletivo ou através de concurso público, o contato foi individual e, nesse momento, falamos da importância e do objetivo do estudo. Esse momento foi realizado com quase todas as funcionárias, entretanto, apenas duas auxiliares e uma professora aceitaram colaborar. E como forma de preservação da identidade das colaboradoras, utilizamos nomes fictícios, sendo que as duas auxiliares de classe foram identificadas na pesquisa como Maria e Ester, e a professora Viviane.

Sobre os aspectos pessoais, a auxiliar de classe Maria tem vinte e oito anos, tem a formação inicial no magistério, é formada em Pedagogia pela Universidade Federal do Recôncavo da Bahia (UFRB), tendo concluído a graduação no ano de 2013. Também possui duas pós-graduações, uma em Educação Especial e a outra em Africanidades. Atuou como docente durante três anos em turmas do terceiro ano dos Anos Iniciais do Ensino Fundamental. Está na instituição desde o ano de 2015, admitida através de concurso público.

A auxiliar de classe Ester tem quarenta anos, tem formação inicial no magistério e é graduada em Educação Física pela URFB, possui pós-graduação em Psicopedagogia. Atuou durante oito anos como docente. Está na instituição desde o início do ano de 2017, admitida por concurso público.

A Professora tem vinte e oito anos, possui graduação em Pedagogia pela UFRB, tendo concluído no ano de 2013. Há sete anos atua na educação. Começou a trabalhar na instituição no início do ano de 2017, admitida através de processo seletivo simplificado.

No que tange aos instrumentos utilizados para a produção dos dados, optamos pela entrevista semiestruturada por permitir as adaptações necessárias no momento da sua realização (LÜDKE e ANDRÉ, 1986). Tal escolha foi motivada por entendermos que, para além de uma simples conversa informal, a entrevista se constituiu como um precioso instrumento para atingirmos os nossos objetivos, pois foi por meio dela que obtivemos informações importantes sobre os sujeitos e sobre o objeto da pesquisa. Acerca disso, Ornellas (2011, p. 29 e 30) assegura que “[...] o pesquisador qualitativo, quando aplica uma entrevista, é uma conversa intencional, com o objetivo de obter dados sobre o objeto que o pesquisador está interessado em estudar.”.

Por opção dos sujeitos da pesquisa a entrevista foi realizada na própria instituição, mas em momentos e dias diferentes. Para a realização da entrevista utilizamos dois roteiros, um com as auxiliares de classe e outro com a professora, mas eles continham perguntas iguais. Ao longo da conversa surgiram outras perguntas além das que estavam no roteiro, e as respostas foram extremamente importantes para o estudo, o que reforçou a necessidade da flexibilidade do 
roteiro, pois proporcionou uma conversa leve, descontraída e as entrevistadas pareciam estar bem à vontade ao responder aos questionamentos.

Diante da necessidade de obtermos mais aspectos acerca do fenômeno, utilizamos também as observações. Esta escolha se deu pela necessidade de registrarmos o fenômeno in loco, e assim, pudéssemos perceber elementos que não são identificados com a utilização de outros instrumentos, como a entrevista, por exemplo. A realização das observações ocorreu em dois dias de realização do planejamento coletivo que aconteceram às segundas-feiras, das 17:00 às 19:00 horas.

No processo de análise dos dados produzidos e escrita nos baseamos na técnica de análise de conteúdo, pois ela é "uma técnica de pesquisa que trabalha com a palavra, permitindo de forma prática e objetiva produzir inferências do conteúdo da comunicação de um texto replicáveis ao seu contexto social." (CAREGNATO e MUTTI, 2006, p. 682). Assim, após coligir os dados, eles foram analisados, e um recorte será apresentado no tópico a seguir.

\section{Cuidado e educação no ato de planejar}

A partir da consideração de que há uma separação entre as pessoas que realizam atividades laborais no âmbito da sala de aula dos Centros de Educação Infantil, principalmente no que tange o desenvolvimento do planejamento das atividades pedagógicas, se tem a necessidade de reflexão acerca da temática, a nossa escolha baseada nesta questão. Entretanto, mesmo com esta separação, ainda é possível encontrarmos a integração do cuidar e do educar, mesmo que sem a intencionalidade de realizá-la.

Diante dessa dualidade, em que há uma separação e, ao mesmo tempo uma junção, fazse necessário trazermos as falas das pessoas que estão diariamente na creche, para podermos compreender como se dá a relação no cotidiano. Além de entender, a partir da categoria aqui analisada, quais as percepções que as auxiliares de classe e a professora têm sobre o binômio cuidar e educar, bem como a relação com a atividade de planejamento.

As questões referentes a essa categoria estavam presentes nos dois roteiros das entrevistas, mas as respostas apontaram elementos diferentes. Quando perguntamos “É possível cuidar sem educar?", na resposta da auxiliar de classe Maria, podemos perceber a concepção da não separação entre o cuidar e o educar, como podemos ver:

Eu acredito que não. E eu aprendi isso aqui. Antes eu achava que eram funções totalmente diferentes, só que quando eu cheguei aqui eu vi que não, que elas estão ligadas ao cuidar e ao educar, eu acho que não existe um sem o outro, principalmente em creche. Porque o tempo todo que a gente "tá" cuidando, por exemplo, quando vai fazer a mediação entre uma briga para que um não morda o outro, a gente ali tá educando, tá ensinando a eles que não pode 
morder, ensinando regras para a sociedade, e também cuidando, evitando que aconteça um acidente. (MARIA, entrevista, 2017).

Na primeira parte da fala podemos observar que a auxiliar coloca que durante as ações diárias foi possível ela perceber a ligação entre o binômio. Concordando, assim, com a ideia apontada por Tiriba (2005, p. 66) de que "O binômio cuidar e educar é, geralmente, compreendido como um processo único, em que às duas ações estão profundamente imbricadas." (grifos da autora). Desse modo, podemos perceber que a profissional compreende que durante a realização das ações de cuidado ela também está educando. Mas qual é a concepção de educar que ela está se referindo?

De acordo com a fala de Maria, é possível notar que a profissional se refere ao educar ligado a vivência em sociedade, ao aprender como se relacionar com o outro. Não abordando questões ligadas ao educar no que diz respeito ao desenvolvimento cognitivo das crianças. Tal concepção de educar apresenta traços parecidos com os dados históricos apontados por Azevedo (2013), que nos diz que a educação de valores e crenças ocorriam desde o surgimento das creches.

A fala da entrevistada também aponta indícios acerca da sua concepção de educação. Dando-nos a entender esta como um processo amplo e que engloba diferentes aspectos do indivíduo. Essa visão reafirma o poder socializador da creche e de como é importante para as crianças conviver com outras pessoas fora do seio familiar.

Ao abordarmos a questão do binômio cuidar e educar, e perguntarmos à professora Viviane, "Um momento de cuidado pode ser também um momento de educar?", ela nos diz que:

Com certeza, o momento de cuidar também é um momento de educar, porque o monitor pode orientar a criança em várias coisas, por exemplo, no horário de comer, como se pega numa colher, no momento do banho, como a criança deve se assear, a importância da higiene do nosso corpo, como se escova o dente, como se penteia os cabelos. Estes também são momentos de a criança aprender. (VIVIANE, entrevista 2017).

Diante da fala da docente, podemos verificar que ela compreende as ações de cuidado como um momento em que pode ocorrer aprendizagens. É possível percebermos que ela trata de aprendizagens ligadas aos aspectos práticos da vida, ou seja, de habilidades que são importantes para o desenvolvimento da autonomia da criança. Aqui consideramos autonomia a partir da concepção de autogovernar-se, ou seja, tratando-a de forma individual. Tal concepção apresentada pela professora traz aspectos positivos e negativos. Positivos, pois se refere à aquisição de habilidades para a conquista da autonomia, que é algo importante para a criança, e deve ser trabalhado e estimulado na creche. Já o lado negativo diz respeito à ideia de que as aprendizagens ligadas ao cuidar se encerram aí no âmbito da prática do cuidado com o corpo. 
Sobre a temática do corpo, a auxiliar de classe Ester nos aponta importantes elementos para refletir, ao afirmar:

Eu estou dando o banho e estou ensinando a elas noções de higiene, as partes do corpo, porque muitas crianças têm aquele nome das partes íntimas, então aquele nome vulgar, usa apelidos e eles acabam esquecendo do nome dos órgãos. Quando eu vou dar banho, que eu digo, olha, tem que lavar o pênis, ele fala "oh pró, a pró não sabe não, 'nué' pênis não, é pinto, pró". Então é essas coisas aí, que a gente começa a educar. E acho que tá assim bem agregado o cuidar e o educar. (ESTER, entrevista, 2017).

A partir de tal colocação podemos perceber que ela traz um exemplo de prática que integra cuidado e educação de maneira parecida com que as outras colaboradoras colocam, mas que dá outros elementos para refletirmos. Pois, quando Ester coloca que ensina noções de higiene, percebemos que a auxiliar está ensinando habilidades importantes para a autonomia, fato que corrobora com a fala da professora Viviane. E quando ela coloca que, durante o banho, ela ensina o nome correto para os órgãos genitais, ela está proporcionando outro conhecimento para as crianças, que vai além dos aspectos práticos. E nesse exemplo citado pela colaboradora temos clara a integração do cuidado e da educação, pois há uma aprendizagem que contempla o binômio, além de tratar a criança como um todo e não como partes.

Além disso, essa prática contempla o conhecimento do próprio corpo, possibilitando a criança o reconhecimento dos órgãos genitais e desenvolvimento de um vocabulário mais elaborado. Outro aspecto importante diz respeito a sexualidade, no que tange o reconhecimento do corpo como seu. Assim, o momento do banho poder ser um ambiente em que a criança entende o limite do toque, entre o que pode e o que não pode ser feito no seu corpo.

Sobre a citação em tela, da auxiliar Ester, ainda é possível observarmos uma relação mais elaborada da integração entre o cuidar e o educar, pois ela coloca novos elementos que não foram abordados pelos outros sujeitos da pesquisa. Além de ampliar as possibilidades de percepção de como ocorre as práticas de cuidado, indica a intencionalidade educativa na sua prática. No que diz respeito sobre essa intencionalidade, Azevedo (2013, p. 100) afirma que:

Um professor que tem clara intenção educativa da sua tarefa vai perceber a importância de uma ação que, julgada por muitos como sendo apenas de cuidado, é também educativa. Numa situação de trocar a fralda de uma criança, as palavras que ele proferir para ela ou os gestos dele que a criança observar nessa interação vão significando o mundo para ela, ampliando seu vocabulário, estimulando sua percepção, atenção etc. A preocupação neste momento não é se o professor está cuidando ou educando, mas a qualidade da interação que ele estabelece com a criança, da compreensão que ele tem da importância daquele momento para o desenvolvimento da criança e, mais uma vez, da intencionalidade educativa que pode estar presente na sua ação, o que vai depender das concepções e conhecimentos do professor sobre as crianças. (AZEVEDO, 2013, p. 100-101). 
A partir das palavras de Azevedo (2013), podemos perceber a importância da intencionalidade para que ocorra de fato a integração efetiva do binômio cuidar e educar. Intencionalidade esta que foi explicitada na fala da auxiliar de classe Ester. Outro fato importante é a percepção e concepção que se tem sobre a criança, pois isso também influenciará na maneira que será desenvolvido todo o trabalho, promovendo ou não a potencialização do desenvolvimento infantil.

Diante das falas apresentadas, foi possível ver que há uma consonância entre às três colaboradoras no que diz respeito à compreensão do momento de cuidado como possibilidade de ser um momento educativo. Entretanto, em outros momentos da entrevista, verificamos que ocorre a separação entre cuidar e educar, principalmente na fala da docente, como podemos observar:

Então, assim, baseado em outras experiências que eu já tive em creche e em outros municípios também, eu acredito que a função dela já é mais voltada para questão do cuidar mesmo. (VIVIANE, entrevista 2017).

[...] por isso que ficou realmente essa separação entre a gente com essa questão, eu fiquei mais com o pedagógico e ela mais com a questão do cuidado com as crianças: banho, asseio, trocar fralda, essas coisas. (VIVIANE, entrevista 2017).

Na fala de Viviane podemos ver traços marcantes dessa separação, fato esse que implica na efetivação de práticas que de fato integrem cuidar e educar. Na perspectiva de integração todas as práticas realizadas na creche seriam com fins pedagógicos, rompendo com a concepção de que apenas as atividades ligadas ao desenvolvimento cognitivo são pedagógicas.

Quando a professora coloca que realmente há essa separação de tarefas, podemos observar, mais uma vez, uma relação hierárquica, marcada pela separação entre a realização do trabalho ligado ao corpo e ao intelecto. E, consequentemente, essa relação se constrói, por vezes, de maneira invisível, mas, às vezes, perceptível na posição hierárquica demarcada entre elas. Essa hierarquia ocasiona uma divisão de tarefas no cotidiano e tem causado consequências nocivas para as crianças e para as trabalhadoras, como apontado por Rosemberg (1994).

Desse modo, podemos perceber o quanto a divisão das tarefas pode ser prejudicial ao desenvolvimento das crianças, uma vez que as práticas realizadas, por vezes, separam corpo e mente. Além de prejudicar o relacionamento entre professoras e auxiliares, fato que contribui de maneira efetiva para a não construção de um trabalho integrado, em que educação e cuidado sejam realizados como um só.

No decorrer das entrevistas a questão do planejamento das atividades pedagógicas apareceu tanto na fala da docente como na fala das auxiliares de classe. Tal fato permitiu que pudéssemos olhar de maneira mais atenta para esse elemento, pois a realização das observações 
ocorreu justamente nos momentos de planejamento coletivo, durante as coordenações pedagógicas, além disso, tal atividade é imprescindível para o trabalho na creche.

O planejamento das atividades é algo importante, pois ele, indica o ponto fundamental da intencionalidade do trabalho a ser desenvolvido, e é o responsável por nortear as ações realizadas no âmbito da sala de aula. Assim, "o planejamento de ensino deve, então, ser elaborado de maneira a fazer progredir o indivíduo" (MARSIGLIA, 2010, p. 102). Desse modo, plano de aula constitui o documento do planejamento e nele devemos ter: o que? para que? o como? e para quem? Pois, são elementos que orientam o desenvolvimento das atividades no âmbito da sala de aula. A construção do planejamento e do plano de aula ocorre no momento da coordenação, e é de responsabilidade das professoras. Porém, as auxiliares participam desses encontros de coordenação, mas não auxiliam na construção do planejamento, na maior parte do tempo elas passam conversando sobre questões pessoais ou acontecimentos cotidianos.

No primeiro dia de observação, durante o momento das discussões de um ponto da pauta da coordenação, a maioria das auxiliares de classe se manifestaram, principalmente porque o ponto fazia referência ao cuidado, pois tratava da questão do banho. A participação pode ter se dado por se tratar de algo referente ao cuidado que é atribuído às auxiliares de classe, por conta da separação entre ações educativas e de cuidado. Em outros momentos houve a participação das auxiliares, mas o que deu para perceber é que apenas algumas delas interagiram, as outras ficam, em sua maioria, caladas, e não participam de maneira ativa nos momentos de discussão referente a outros assuntos. O que demonstra a restrição destas mulheres no ambiente de trabalho, marcando uma separação em quais aspectos elas podem ser envolvidas e quando devem ser silenciadas.

Já no momento destinado à construção do planejamento pedagógico semanal, não houve a participação das auxiliares de classe no processo. O que demonstra, mais uma vez, a não integralidade das ações de cuidado e educação no âmbito da creche. No período em que as professoras planejavam, algumas auxiliares de classe se reuniram para conversar, outras utilizavam o celular, e uma conversava com uma professora que parecia já ter feito o plano ou faria em outro momento. O cenário foi o mesmo nos dois encontros, fato que aponta que não há um entrosamento entre as professoras e auxiliares de classe no momento do planejamento. Assim, as auxiliares de classe não sabem quais atividades serão realizadas na semana seguinte, salvo em datas comemorativas ou eventos, uma vez que se faz necessário a mão de obra para que os eventos ocorram.

No momento da entrevista, quando perguntamos a auxiliar de classe Maria sobre a participação das auxiliares na realização dos planejamentos, ela respondeu de maneira taxativa que era "Nenhuma" (MARIA, entrevista 2017), deixando ainda mais explícito o não 
envolvimento delas, nesse momento. Tal fato é novamente evidenciado por meio da fala da professora que ao ser questionada sobre a participação das auxiliares de classe no planejamento assegura que:

No meu caso, a minha não se senta perto de mim no horário do planejamento "né", ela se senta perto das outras monitoras e conversa, eu e a outra professora que fazemos os planos de aula, ela não se envolve assim, muito no pedagógico não. Auxilia assim, se eu pedir para fazer alguma coisa, me ajuda a aplicar uma atividade, mas a questão pedagógica fica exclusivamente comigo. Pelo menos essa que trabalha comigo existe essa separação. (VIVIANE, entrevista 2017).

Na primeira linha encontramos uma palavra que nesse contexto demarca uma relação de poder. A expressão "minha" dá a conotação de objeto para a auxiliar de classe e explicita a relação de poder estabelecida entre docente e auxiliar. Tal fato demonstra uma hierarquização como foi afirmado por Cerisara:

A dinâmica das relações estabelecidas entre auxiliares de sala e as professoras das instituições de educação infantil, que trabalham junto ao mesmo grupo de crianças, deve ser analisada levando em consideração a existência de uma hierarquização oficial entre as duas. Essa hierarquização tem sido evidenciada por meio de indicadores concretos, tais como: carga horária semanal de trabalho, salário, formação e divisão de tarefas. (CERISARA, 2002, p. 72).

Com os elementos apontados pela autora, podemos perceber as condições diferentes que se encontram professoras e auxiliares de classe, fato que nos indica o porquê da ideia de poder apresentada na fala da professora. Também podemos notar a ideia do auxílio, da ajuda, e não a realização de um trabalho tão significativo quanto o desenvolvido pelas professoras. Além disso, é possível perceber que, já no final da sua fala, a Viviane se refere à auxiliar de outra maneira.

Nos elementos referentes ao planejamento, a docente afirma que a auxiliar não se envolve e fica conversando com outras colegas, fato esse que pôde ser observado durante as nossas participações na coordenação e citado na fala da professora Viviane. Esse não envolvimento no planejamento demarca o lugar da auxiliar na instituição, pois demonstra que a sua função se destina tão somente ao cuidado, além de apontar que ele é visto apenas como atividades práticas que garantem apenas o bem-estar das crianças, não sendo necessário o planejamento, pois não tem intencionalidade pedagógica.

Tal realidade relatada pela professora Viviane diverge com as atribuições das auxiliares de classe dispostas no Plano de cargos e carreira do município de Amargosa. No documento sobre as atribuições encontramos:

Participa do planejamento, executa e avalia atividades educacionais no âmbito da educação infantil (creche) da Secretaria Municipal da Educação, em 
consonância com normas e critérios do planejamento nacional da educação e dos planos estadual e municipal. (AMARGOSA, 2009, p. 36).

Colocada a participação no planejamento, entende-se que ela não deveria ser meramente figurativa, e sim opinando e contribuindo para a construção das atividades. Pois, de acordo com a fala da professora Viviane, a auxiliar de classe em alguns momentos da realização das atividades pedagógicas ajuda a docente, fato que aconteceria de maneira mais produtiva se a trabalhadora tivesse conhecimento antecipado acerca das atividades pensadas para a turma na qual atua.

Tendo confirmada a não participação nas atividades de planejamento, questionamos se ocorria a participação das auxiliares de classe em outras atividades, Maria, que realiza essa função, coloca que:

A gente faz os materiais, confecciona os materiais em sala de aula no momento em que os meninos estão dormindo, mas, assim, no momento de coordenação, a gente não participa. (MARIA, entrevista 2017).

Desta forma, podemos perceber que as auxiliares de classe colaboram como mão de obra para a realização de tarefas manuais. E ao colocar essa não participação no planejamento, Maria mostrou um certo descontentamento, através de sua expressão corporal, facial e entonação vocal, o que demonstra um interesse em participar de tal atividade.

Diante de tal insatisfação, notada nas expressões da auxiliar de classe, entendemos que seria necessário irmos mais fundo nessa temática e questionar à docente sobre a sua percepção sobre a postura das auxiliares de classe e sobre a participação no planejamento. Assim, perguntamos para a professora Viviane se ela percebia nas auxiliares a vontade de participarem do planejamento, então ela foi taxativa respondendo que não, e completou dizendo que:

As auxiliares reclamam que vão para o planejamento e ficam sem ter o que fazer, porque quem faz o planejamento é o professor não é o auxiliar, "né"? Então eles se sentem um peixe fora d'água, até porque quando eles são envolvidos é no momento dos avisos ou quando precisa de alguma ajuda para fazer alguma lembrancinha, algo que eles levem para o momento de planejamento, não tem assim a parte de uma formação contínua específica para o monitor no momento de planejamento. Então, de certa forma, elas se sentem, às vezes, um peixe fora d'água, como eu falei "né"? Eles, eu acredito que para eles o planejamento não tem muito sentido, só a questão dos avisos mesmo, tem mais sentido para o professor. (VIVIANE, entrevista 2017).

Um fato importante apontado pela professora diz respeito a falta de momentos formativos voltados para as auxiliares de classe. Tal fato pode indicar a presença de uma concepção de que para a realização das atividades de cuidar não são necessários processos formativos. Outro item que a aparece na fala da docente diz respeito a não participação das 
auxiliares de classe no planejamento. A sua negativa se contrapõe ao demonstrado pela auxiliar de classe Maria, evidenciando uma possível monopolização do planejamento por parte das professoras. Tal fato é reforçado quando a professora afirma que:

Porque quem faz o planejamento é o professor não é o auxiliar, "né"? (VIVIANE, entrevista 2017).

A citação acima demonstra um entendimento de que as ações realizadas pelas auxiliares de classe não precisam ser planejadas. Ainda é possível notarmos que a docente se refere a participação no planejamento como a participação nos momentos de coordenação. Colocando que por não terem nenhuma atividade, salvo nos momentos dos avisos, demonstra o não interesse pelo planejamento por parte das auxiliares. Percebemos tal fato de maneira diferente, pois entendemos que o não envolvimento na construção do planejamento tem por consequência a ociosidade das auxiliares durante a coordenação, pois nos momentos que foram envolvidas elas se mostraram participativas.

De acordo com os dados, percebemos que as auxiliares de classe não são "um peixe fora d'água", como colocado pela docente, e sim um peixe tirado d'água. Pois, não é dado a oportunidade para auxiliares opinarem e colaborarem, ou seja, participar de maneira ativa na construção do planejamento pedagógico. Também não é dado a elas a oportunidade de incluírem as suas atividades no planejamento como atividades pedagógicas. Essa não participação no planejamento aponta para o lugar profissional ocupado pela auxiliar de classe e reforça a separação entre o binômio. Além disso, tais falas podem apontar a ideia de que o cuidar se realiza na improvisação e que não faz parte da rotina pedagógica.

Por fim, percebemos a demarcação da função da auxiliar de classe ligada exclusivamente ao cuidar, e a professora realiza o educar, ocasionando uma divisão social do trabalho, reafirmando as demarcações acerca do lugar profissional. Tais dados vão na contramão do que tem se discutido acerca da indissociabilidade das ações de cuidado e educação. Por vezes as auxiliares de classe e a professora apontam em suas falas a integração do cuidar e do educar e a sua importância, mas em outros momentos, ao tratarem dos aspectos cotidianos, demonstram que a integração não tem se efetivado no chão das salas da Educação Infantil. Confirmando assim, conforme Azevedo (2013), que cuidar e educar virou slogan, mas que não tem se efetivado no cotidiano. Entretanto, tal realidade pode ser modificada através de novas condições e relações de trabalho que busque eliminar a divisão entre as funções, além do reconhecimento das especificidades do trabalho profissional no âmbito das instituições que atendem a primeira infância, e efetive o que preconiza de fato a lei. 


\section{Palavras Finais}

Ao tratarmos acerca do binômio cuidar e educar na creche e das relações laborais que se estabelecem nesses espaços, mas especificamente as ações de planejamento pedagógico das atividades, optamos por debater a separação existente entre as mulheres que desempenham ações laborais no âmbito da creche. Mas, mesmo com essa separação, é possível observar o quanto esse binômio é indissociável nas atividades, e que é preciso uma reflexão para que as práticas sejam repensadas com vista a integralizar de forma efetiva as ações de cuidado e de educação podendo, assim, potencializar o processo educativo das crianças que frequentam as instituições.

Além disso, é preciso o reconhecimento e a efetivação das práticas que envolvam o cuidado como atividades pedagógicas, que para serem executadas precisam de planejamento e intencionalidade. Objetiva-se, assim, a proposição de ações que ultrapassem o cuidado como apenas uma citação no plano de aula diário do professor, e possam apresentar uma intencionalidade de ensino.

Assim, a partir das informações e reflexões expostas ao longo do texto, podemos perceber o quanto são complexas as questões referentes ao binômio cuidar e educar. Em algumas situações durante as entrevistas, as trabalhadoras apontaram a importância da integração, e até conseguiram indicar as possibilidades de ações para a efetivação da indissociabilidade do cuidar e do educar, contudo, em outros momentos da observação, foi possível identificar a possibilidade de uma separação. Diante desta situação, nos cabe concordar com Azevedo (2013) que afirma que ainda não fomos capazes de superar a separação, pois é provável que ainda não tenha ocorrido uma compreensão de fato por parte das profissionais da Educação Infantil do que significa a integração do binômio. É preciso dizer que essa superação não se configura como algo fácil. Mas ela é possível, com ações que incluam processos formativos que evidenciem os aspectos pedagógicos dos atos de cuidado, além disso, a reestruturação no que tange a divisão entre as trabalhadoras, reconhecendo que cuidar e educar são atribuiçõos docentes.

\section{REFERÊNCIAS:}

ABRAMOWICZ, Anete. O direito das crianças à educação infantil. Proposições. v. 14, n. 3 (42) - set./dez. 2003.

AMARGOSA. Lei $\mathbf{N}^{\mathbf{0}} .318$ de 31 de dezembro de 2009. Dispõe sobre a estruturação do Plano de Cargo e Carreira da rede pública municipal de ensino de Amargosa e dá providências correlatas. Amargosa, 2009. 
AZEVEDO, Heloisa Helena Oliveira de. Educação Infantil e Formação de Professores: para além da separação cuidar-educar. 1. ed. - São Paulo: Editora Unesp, 2013.

BRASIL. Listagem das profissões regulamentadas: normas regulamentadoras. Cadastro Brasileiro de Ocupações. Disponível em < http://www.mtecbo.gov.br/cbosite/pages/regulamentacao.jsf $>$. Acesso em 24 de fevereiro de 2020.

Lei no 9.394, de 20 de dezembro de 1996. Lei de Diretrizes e Bases da Educação Nacional: que estabelece as diretrizes e bases da educação nacional, 1996. Disponível em: < https://www.planalto.gov.br/ccivil_03/Leis/L9394.htm >. Acesso em 03 de janeiro de 2020.

Ministério da Educação. Secretaria de Educação Básica. Diretrizes curriculares nacionais para a educação infantil / Secretaria de Educação Básica. - Brasília: MEC, SEB, 2010 .

CAMPOS, Maria Malta. Educar e cuidar: questões sobre o perfil do profissional de Educação Infantil. In: Por uma Política de Formação do Profissional de Educação Infantil. Brasília: MEC/SEF/DPE/COEDI, 1994. p.31-42.

CAREGNATO, Rita Catalina Aquino; MUTTI, Regina. Pesquisa qualitativa: análise de discurso versus análise de conteúdo. Texto Contexto Enferm, Florianópolis, 2006 Out-Dez; 15(4): 679-84.

CERISARA, Ana Beatriz. Professoras de Educação Infantil: entre o feminino e o profissional. Coleção Questões da Nossa Época. São Paulo: Cortez, 2002.

CORDEIRO, Karina de Oliveira Santos Cordeiro; SODRÉ, Liana Pontes Gonçalves. A implantação da Educação Infantil no município de Teixeira de Freitas - Bahia. Revista Práxis Educacional, Vitória da Conquista, v.4, n, 5, p. 109-127, jul/dez. 2008. Disponível em: https://periodicos2.uesb.br/index.php/praxis/article/view/579/473. Acesso em: 21 de jan. de 2021.

DUBAR, Claude. A Socialização: Construção das Identidades Sociais e Profissionais. Tradução: Andréa Stahell M. da Silva. São Paulo: Martins Fontes, 2005.

ESTEBAN, Maria Paz Sandín. Pesquisa Qualitativa em Educação: Fundamentos e Tradições. Tradução Miguel Cabrea. Porto Alegre: AMGH, 2010.

FREIRE, Zildiane de Jesus; FERREIRA, Lucia Gracia. Saberes e fazeres de professoras da educação infantil. REVISTA FORMAÇÃO@DOCENTE - belo horizonte - v. 12, n. 2, julho/dezembro 2020. p.1-25. Disponível em: < https://www.metodista.br/revistas/revistasizabela/index.php/fdc/article/view/1805/1146 >. Acesso em 23 de janeiro de 2021.

KULHMANN Jr, Moysés. Educando a Infância Brasileira. In: LOPES, Eliane Marta Teixeira; FARIA FILHO, Luciano Mendes de; VEIGA, Cynthia Greive (Orgs). 500 Anos de Educação no Brasil. Belo horizonte: Autêntica, 2000.

LÜDKE, Menga; ANDRÉ, Marli E. D. A; Pesquisa em Educação: Abordagens Qualitativas. São Paulo: EPU, 1986. 
MARSIGLIA, Ana Carolina Galvão. Relações entre o desenvolvimento Infantil e o planejamento de ensino. In: MARTINS, LM. DUARTE, N. (Orgs). Formação de professores: limites contemporâneos e alternativas necessárias. [online]. São Paulo: Editora UNESP; São Paulo: Cultura Acadêmica, 2010. p. 99- 119.

ORNELLAS, Maria de Lurdes S. [Entre]vista: A Escuta Revela. Salvador: EDUFBA 2011.

ROSEMBERG, Fulvia. Formação do Profissional de Educação Infantil, Através de Cursos Súpleteos. In: Por uma Política de Formação do Profissional de Educação Infantil. Brasília: MEC/SEF/DPE/COEDI, 1994.

SILVA, Carmem Virgínia Moraes da; FRANCISCHINI, Rosângela. O surgimento da educação infantil na história das políticas públicas para a criança no Brasil. Revista Práxis Educacional, Vitória da Conquista, v.8, n. 12, p. 257-276, jan/jul. 2008. Disponível em: https://periodicos2.uesb.br/index.php/praxis/article/view/699/584 . Acesso em 10 de jan. de 2021.

SOUZA, Jorsinai de Argolo; RIOS, Jane Adriana Vasconcelos Pacheco; OLIVEIRA, Rosemary Lapa de. Políticas Públicas para a Educação Infantil: um debate sobre a expansão da oferta e a formação dos professores. Revista de Estudos em Educação e Diversidade REED, [S.L.], v.1, n.2, p. 392-409, 2020. Disponível em: https://periodicos2.uesb.br/index.php/reed/article/view/7900/5436 . Acesso em: 29 de jan. 2021.

TIRIBA, Léa. Educar e Cuidar: Buscando a Teoria para Compreender os Discursos e as Práticas. In: KRAMER, Sonia (Org.). Profissionais da Educação Infantil: Gestão e Formação. São Paulo: Ática, 2005.

\section{SOBRE AS AUTORAS:}

\section{Livia Karen Figueredo de Jesus}

Mestranda no Programa de Pós-graduação em Educação da Faculdade de Educação da Universidade Federal da Bahia (UFBA). Participa do Grupo de Estudos e Pesquisas em Educação, Didática e Ludicidade (GEPEL) do Programa de Pós-Graduação em Educação da FACED/UFBA. Bolsista da Coordenação de Aperfeiçoamento de Pessoal de Nível Superior (CAPES). E-mail: livia.karen@ hotmail.com

(iD) https://orcid.org/0000-0003-0845-4931

\section{Karina de Oliveira Santos Cordeiro}

Pós-Doutora em Educação pela Universidade Federal de Minas Gerais (UFMG), Doutora em Educação pela Universidade Federal da Bahia (UFBA) e Mestre em Educação pela Universidade do Estado da Bahia (UNEB). Professora Adjunta da Universidade Federal do Recôncavo da Bahia (UFRB); Membro do Grupo de Pesquisa Infâncias, Formação de professores e Políticas Públicas (GRIFO/UFRB). E-mail: koscordeiro@ufrb.edu.br

(iD) https://orcid.org/0000-0002-9136-1383 